\title{
Mechanical Characteristics of Frozen Sandstone under Lateral Unloading: An Experimental Study
}

\author{
Shuai Liu $\mathbb{D}^{1},{ }^{1}$ Gengshe Yang, ${ }^{1}$ Xihao Dong, ${ }^{1}$ Yanjun Shen, ${ }^{2,3}$ and Hui Liu ${ }^{1}$ \\ ${ }^{1}$ School of Architecture and Civil Engineering, Xi'an University of Science and Technology, Xi'an, Shaanxi 710054, China \\ ${ }^{2}$ School of Geology and Environment, Xi'an University of Science and Technology, Xi'an, Shaanxi 710054, China \\ ${ }^{3}$ Geological Research Institute for Coal Green Mining, Xi'an University of Science and Technology, Xi'an, Shaanxi 710054, China
}

Correspondence should be addressed to Shuai Liu; 614297281@qq.com

Received 8 November 2020; Revised 25 March 2021; Accepted 10 April 2021; Published 21 April 2021

Academic Editor: Damien Rangeard

Copyright (C) 2021 Shuai Liu et al. This is an open access article distributed under the Creative Commons Attribution License, which permits unrestricted use, distribution, and reproduction in any medium, provided the original work is properly cited.

\begin{abstract}
The lateral unloading strength and deformation of surrounding frozen rock are the key parameters for safety evaluation of frozen shaft construction. A low-temperature and high-pressure rock triaxial test system was used to simulate freezing construction, and a constant axial pressure unloading confining pressure test was carried out on frozen sandstone. The effects of freezing temperature, initial confining pressure, and unloading rate on the strength, deformation, and failure modes of frozen sandstone are studied. The main results of the study are as follows: (1) under the initial confining pressure of $20 \mathrm{MPa}$, the temperature of the sandstone decreases from $20^{\circ} \mathrm{C}$ to $-5^{\circ} \mathrm{C}$, and the peak stress and elastic modulus of triaxial compression increase by approximately 3 times. Under lateral unloading conditions, the peak stress of frozen sandstone is about $2 \sim 3$ times that of $20^{\circ} \mathrm{C}$ sandstone, and the peak strain of $20^{\circ} \mathrm{C}$ sandstone is smaller than that of frozen sandstone. The temperature of frozen sandstone decreases and the rate of increase in the peak stress of triaxial compression is slightly less than the rate of increase in the peak stress of lateral unloading. (2) The initial confining pressure of frozen sandstone increases, the growth rate of axial and radial strain increases, the radial strain dominates the failure process, and the lateral unloading strength decreases significantly. (3) The lateral unloading rate of frozen sandstone increases, the peak strength increases, and the axial and radial strain decrease. At a low unloading rate, partial creep deformation occurs. (4) The frozen rock sample undergoes tensile splitting failure under lateral unloading. According to the stress-strain curve of the frozen rock sample, the relationship between changes in the deformation modulus and changes in the confining pressure unloading amount during the unloading process of the rock sample is obtained.
\end{abstract}

\section{Introduction}

When mining deep coal resources, the artificial freezing method is often used to cross deep water-rich soft rock strata. The freezing of the shaft wall can block the leakage of groundwater, provide a watertight working environment, and improve the strength and deformation resistance of the excavated rock and soil [1]. Temperature has a substantial influence on the mechanical behavior of rock and soil. Excavating a frozen shaft is equivalent to lateral unloading of frozen rock. Studying the mechanical characteristics of frozen rock lateral unloading is very important to the construction design of the frozen shaft.

With the development of artificial freezing construction technology and cold area engineering, useful results have been achieved in research related to the mechanical properties of frozen rock. The unfrozen water content of saturated rock decreases with the decrease of freezing temperature, which has a great influence on the strength and deformation [2]. Shen et al. [3] studied the water migration and phase change of sandstone as the two core factors of freezing $\left(20^{\circ} \mathrm{C} \longrightarrow-30^{\circ} \mathrm{C}\right)$ damage. Liu et al. [4] concluded that the peak strength of saturated silty mudstone under uniaxial compression has a parabolic relationship with temperature, and the axial strain at peak strength has a linear relationship with temperature. Kodama et al. [5] concluded that the strength of water-containing rock is inversely proportional to temperature. Gao et al. [6] concluded that the average fracture toughness of frozen sandstone was $10.47 \% \sim 158.33 \%$ higher than that of normal temperature 
sandstone. Shan et al. [7] conducted an impact test on red sandstone at $-15^{\circ} \mathrm{C}$. The strength, deformation, and failure modes of frozen red sandstone are related to the strain rate. Jia et al. [8] concluded that the tensile strength of saturated coal and rock increased below $0^{\circ} \mathrm{C}$. Yue et al. [9] concluded that as the temperature of coal decreases, the compressive strength and tensile strength increase linearly. Li et al. [10] revealed that the strength of ice crystals, the strength of the particle mixture, the friction strength between blocks, and the occlusal strength are the main factors affecting the uniaxial compressive strength of the frozen soil rock mixture and the ice crystals improve the bearing capacity and ductility. Xia et al. [11] proposed the transverse isotropy of frost heave under the condition of unidirectional freezing of saturated rock. Yu et al. [12] showed that the number of freeze-thaw cycles has an important influence on uniaxial compressive strength, elastic modulus, internal friction angle, and cohesion. Vikram and Julian [13] used a CT scan to observe the development and penetration of microcracks during 20 freeze-thaw cycles. Fang et al. [14] studied the failure characteristics of yellow sandstone under triaxial compression under the action of chemical corrosion and freeze-thaw cycles. Freeze-thaw damage mainly occurs during freezing, and chemical corrosion mainly occurs during thawing. Han et al. [15] concluded that under the combined action of chemical solutions and freeze-thaw cycles, the fracture toughness of sandstone deteriorated the most, followed by the tensile strength, while the compressive strength deteriorated relatively little.

Studying the deformation and failure of frozen rock under triaxial compression is a prerequisite for understanding the mechanical properties of frozen rock under lateral unloading. The artificial freezing method is adopted for construction, and the initial spatial stress redistribution caused by the excavation of the frozen shaft can be regarded as a process in which the axial stress remains unchanged and the horizontal stress gradually decreases. This process will inevitably produce lateral unloading deformation. Extant research has tended to carry out constant axial pressure unloading confining pressure tests at room temperature in the laboratory and study the size and deformation parameters of the lateral unloading deformation of normal temperature rock. Qiu et al. [16] found that when the unloading confining pressure accounts for $60 \%$ of the initial confining pressure, it is usually the boundary point between linear and nonlinear unstable damage. Yang $[17,18]$ concluded that under the same confining pressure, the peak strain of the lateral unloading test of red sandstone is higher than that of the triaxial compression test, and the confining pressure has a significant influence on the failure mode. Xu et al. [19] carried out an unloading confining pressure test of brittle rock samples and found that Poisson's ratio increases as the confining pressure increases, and the confining pressure has a certain softening effect. Zhang et al. [20] showed that as the unloading rate decreases, the axial strain and radial strain of the rock sample first decrease and then increase. Zhao et al. [21] used a true triaxial test system to explore the effect of unloading rate on granite strain. Huang et al. [22] carried out a sandstone lateral unloading test and obtained the damage evolution law related to the unloading rate, and the continuous unloading confining pressure exhibited an approximately linear relationship with strain softening. Feng et al. [23] obtained the failure characteristics of hard rock with holes under different unloading rates and different in situ stresses. Huang and Li [24] suggested that the conversion rate of strain energy in the unloading test is much greater than the conversion rate of strain energy in the compression test. The higher the unloading rate and the initial compressive stress, the more serious the rockburst. Duan et al. [25] concluded that the higher the unloading rate of granite, the more serious the damage, the greater the lateral expansion and deformation, and the more the debris. He et al. [26] and Xu et al. [27] undertook true triaxial unloading tests on limestone and marble and studied the effects of initial stress and unloading rate on deformation and failure mechanisms. Xiao et al. [28] carried out a constant axial pressure unloading test on rock with fissures. When the fissure inclination angle of the rock sample is $0^{\circ}$ or $30^{\circ}$, and the confining pressure unloading amount is less than $75 \%$, the confining pressure unloading amount exhibits a linear relationship with the amount of change in the deformation modulus. Using discrete element software, Li et al. [29] applied the unloading relaxation method to study the influence of stress path on excavation unloading.

Most scholars at home and abroad have explored the deformation and failure characteristics of normal temperature rock lateral unloading and have not considered the effect of freezing on these phenomena. In this article, considering the effect of low-temperature freezing, lateral unloading tests of frozen sandstone under different initial confining pressures and different unloading rates are carried out to identify the impacts on lateral unloading strength and deformation. According to the stress and strain, the confining pressure unloading amount and the change in the deformation modulus are calculated and explored.

\section{Test Content}

2.1. Sample Preparation. Cretaceous water-rich sandstone blocks from the Binchang mining area, Shaanxi Province, China, were drilled and cored along the vertical bedding direction. Drilling, cutting, and grinding were used to obtain standard cylindrical samples $(\varphi=50 \mathrm{~mm}, H=100 \mathrm{~mm})$ based on the requirements of international standards. All the rock samples were taken from the same rock, as shown in Figure 1. This rock was dark red, with obvious bedding, large particles, large pores, and weak cementation. A vacuum saturation device was used to saturate the rock sample. To reduce the dispersion, rock samples with similar longitudinal wave velocities were selected, with an average wave velocity of $2410 \mathrm{~m} / \mathrm{s}$.

2.2. Test Instruments. The RTX-1500 electrohydraulic servo control low-temperature and high-pressure triaxial rock test system (GCTS company, United States) was used for the mechanical test of the frozen sandstone, as shown in Figure 2. A refrigeration circulator (JULABO FP75) controlled the temperature of the triaxial pressure chamber in real time during the test. The temperature control range was $-30^{\circ} \mathrm{C}$ 


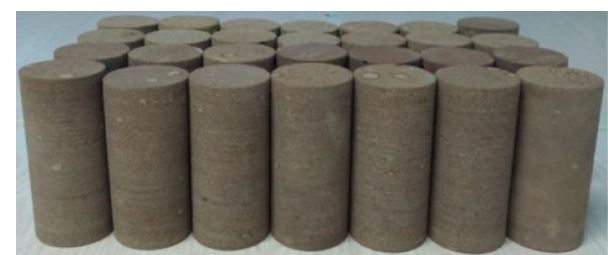

FigURE 1: Rock samples.

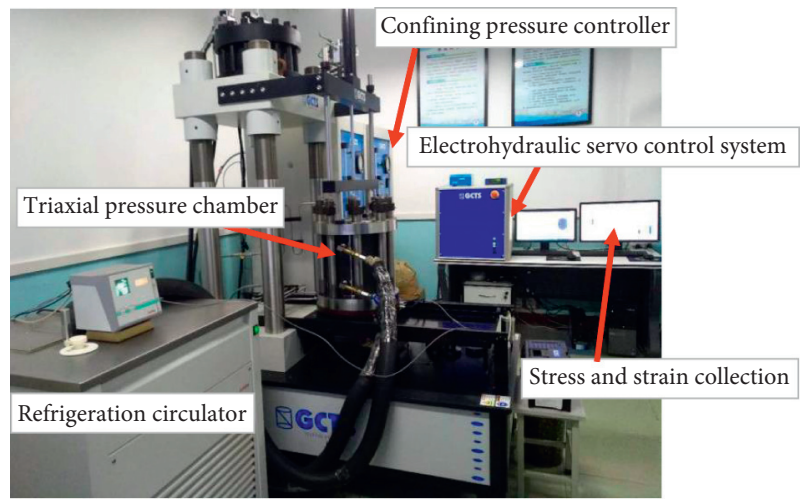

Figure 2: Electrohydraulic servo control low-temperature and high-pressure rock three-axis test system.

to $+80^{\circ} \mathrm{C}$, with an accuracy of $\pm 0.05^{\circ} \mathrm{C}$. The maximum confining pressure of the instrument is $140 \mathrm{MPa}$, the maximum axial pressure is $1500 \mathrm{kN}$, and the accuracy is $0.1 \%$. The stress and strain data of rock samples were obtained in real time.

2.3. Test Plan. During the construction process of the artificial freezing method, the temperature of the internal and external freezing walls was about $-6.3^{\circ} \mathrm{C} \sim-16.8^{\circ} \mathrm{C}[30]$. The test temperatures were set to $-5{ }^{\circ} \mathrm{C},-10^{\circ} \mathrm{C}$, and $-15^{\circ} \mathrm{C}$, and these were compared with the rock sample at room temperature $\left(20^{\circ} \mathrm{C}\right)$. Rock strata with different buried depths have different stress states. According to the rock buried depth, the existing coal mine shaft freezing depth in China has reached more than $1 \mathrm{~km}$. It is expected that the freezing depth will continue to increase in the future. During the active freezing period, the water phase changes into ice, resulting in volume expansion and an increase in pore pressure, which increases the ground stress. The confining pressure during the test was set to $10 \mathrm{MPa}, 20 \mathrm{MPa}$, and $30 \mathrm{MPa}$.

A triaxial compression test (TCT) of sandstone was carried out at different temperatures $\left(20^{\circ} \mathrm{C},-5,-10^{\circ} \mathrm{C}\right.$, and $-15^{\circ} \mathrm{C}$ ) under $20 \mathrm{MPa}$ confining pressure. Further, a TCT of sandstone at $-10^{\circ} \mathrm{C}$ was carried out under different confining pressures $(10 \mathrm{MPa}, 20 \mathrm{MPa}$, and $30 \mathrm{MPa})$. The initial axial compression of the frozen sandstone lateral unloading test (LUT) was based on $70 \%$ (the corresponding stress level when the volumetric strain rotates) of the triaxial compression strength. The test plan for lateral unloading of frozen sandstone is shown in Table 1.

\subsection{Test Procedure}

(1) Petroleum jelly was evenly spread on the surface of the saturated rock sample; it was put on a rubber mold. The rock sample was fixed on the base and the deformation measuring device was installed as shown in Figure 3. After sealing the pressure chamber, antifreeze liquid was injected and cotton was used for insulation.

(2) At a cooling rate of $10^{\circ} \mathrm{C} / \mathrm{h}$, the temperature of the rock sample was reduced from room temperature to the set freezing temperature, and the temperature was kept constant for 10 hours.

(3) The LUT was conducted using the stress control mode to simulate the excavation unloading of a freezing shaft. The axial stress remained unchanged, and the horizontal stress gradually decreased. The stress path is shown in Figure 4. First, a particular confining pressure was applied $\left(\sigma_{1}=\sigma_{2}=\sigma_{3}\right)$ to the set value (o) (a) at a rate of $0.5 \mathrm{MPa} / \mathrm{min}$, and the confining pressure was stabilized for 2 minutes. The confining pressure was kept fixed and axial pressure $\left(\sigma_{1}\right)$ was applied at a rate of $3 \mathrm{MPa} / \mathrm{min}$ to $70 \%(\mathrm{a}, \mathrm{b})$ of the triaxial compressive strength (TCS) of the rock sample under the same confining pressure. The axial pressure was then stabilized for 2 minutes. Keeping the axial pressure $\left(\sigma_{1}\right)$ constant, the confining pressure $\left(\sigma_{3}\right)$ was reduced at a certain unloading rate until the rock sample was broken (b c $\longrightarrow \mathrm{c} d$ ). The rock sample always maintained a constant temperature during the entire loading and unloading process.

(4) Stress and strain data spanning the entire process of frozen sandstone LUT were obtained.

\section{Test Results and Analysis}

3.1. Stress-Strain Curve of Frozen Sandstone under Triaxial Compression. The stress and strain of frozen sandstone under triaxial compression are studied to provide initial axial compression for the LUT of frozen sandstone. The relationship between deviator stress $\left(\sigma_{1}-\sigma_{3}\right)$ and axial strain $\left(\varepsilon_{1}\right)$ of rock samples at different temperatures $\left(\sigma_{3}=20 \mathrm{MPa}\right)$ in triaxial compression is shown in Figure 5. In the rock samples at different temperatures, the initial cracks are closed during the confining pressure loading stage, and the stress-strain curve at the early stage of axial loading is approximately linear. The deviator stress continues to increase, entering the plastic yield stage, and the stress-strain curve is convex upward. The axial strain in the plastic yielding stage of the $20{ }^{\circ} \mathrm{C}$ rock sample is greater than that of the frozen rock sample. After the peak stress, the internal crack propagates and penetrates, and the lower the temperature, the faster the deviatoric stress decay rate. At a confining pressure of $20 \mathrm{MPa}$, the temperature of the rock sample drops from $20^{\circ} \mathrm{C}$ to $-15^{\circ} \mathrm{C}$, the peak stress increases, and the peak strain decreases. From $20^{\circ} \mathrm{C}$ to $-5^{\circ} \mathrm{C}$, the peak stress increases by approximately 3 times. The freezing temperature decreases and the peak stress of the rock sample slowly increases. 
TABLE 1: Lateral unloading test plan.

\begin{tabular}{|c|c|c|c|c|c|c|}
\hline $\begin{array}{l}\text { Rock } \\
\text { sample } \\
\text { number }\end{array}$ & $\begin{array}{c}\text { Temperature } \mathrm{T} \\
\left({ }^{\circ} \mathrm{C}\right)\end{array}$ & $\begin{array}{c}\text { Initial confining } \\
\text { pressure } \sigma_{3}^{0}(\mathrm{MPa})\end{array}$ & $\begin{array}{l}\text { Initial axial } \\
\text { pressure } \sigma_{1}^{0} \\
(\mathrm{MPa})\end{array}$ & $\begin{array}{l}\text { Unloading rate } \\
V_{u}(\mathrm{MPa} / \mathrm{min})\end{array}$ & Test & Test content \\
\hline LUT-1 & 20 & 20 & 26 & 0.2 & \multirow{8}{*}{$\begin{array}{l}\text { Lateral unloading } \\
\text { mechanics test }\end{array}$} & \multirow{8}{*}{$\begin{array}{l}\text { Confining pressure, axia } \\
\text { stress, radial strain, axia } \\
\text { strain }\end{array}$} \\
\hline LUT-2 & -5 & 20 & 42 & 0.2 & & \\
\hline LUT-5 & & 10 & 40 & 0.2 & & \\
\hline LUT-7 & & & 50 & 0.04 & & \\
\hline LUT-3 & -10 & 20 & 50 & 0.2 & & \\
\hline LUT-8 & & & 50 & 4.0 & & \\
\hline LUT-6 & & 30 & 55 & 0.2 & & \\
\hline LUT-4 & -15 & 20 & 50 & 0.2 & & \\
\hline
\end{tabular}

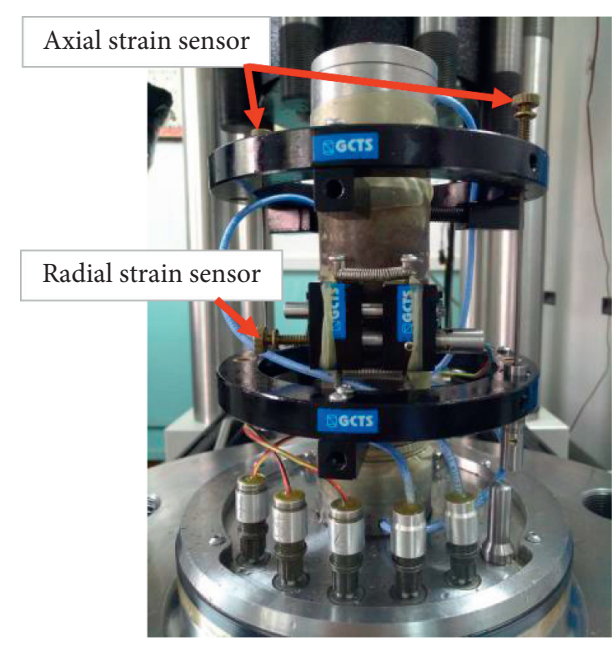

Figure 3: Deformation measuring device.

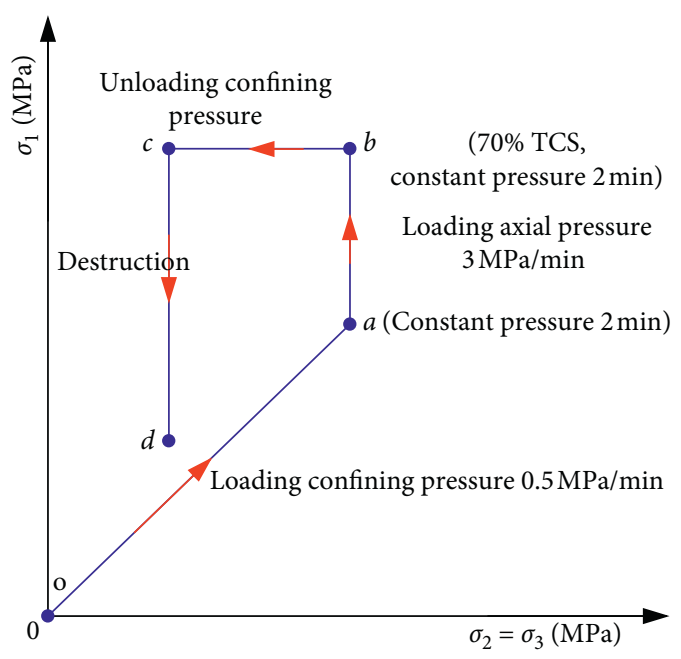

Figure 4: Stress path of lateral unloading test.

The relationship between deviator stress $\left(\sigma_{1}-\sigma_{3}\right)$ and axial strain $\left(\varepsilon_{1}\right)$ in triaxial compression for $-10^{\circ} \mathrm{C}$ sandstone under different confining pressures is shown in Figure 6. As the confining pressure increases, the rate of increase of the stress-strain curve in the elastic stage gradually becomes larger, the yield stage becomes longer, the crack density increases, and the slope of the stress-strain curve gradually

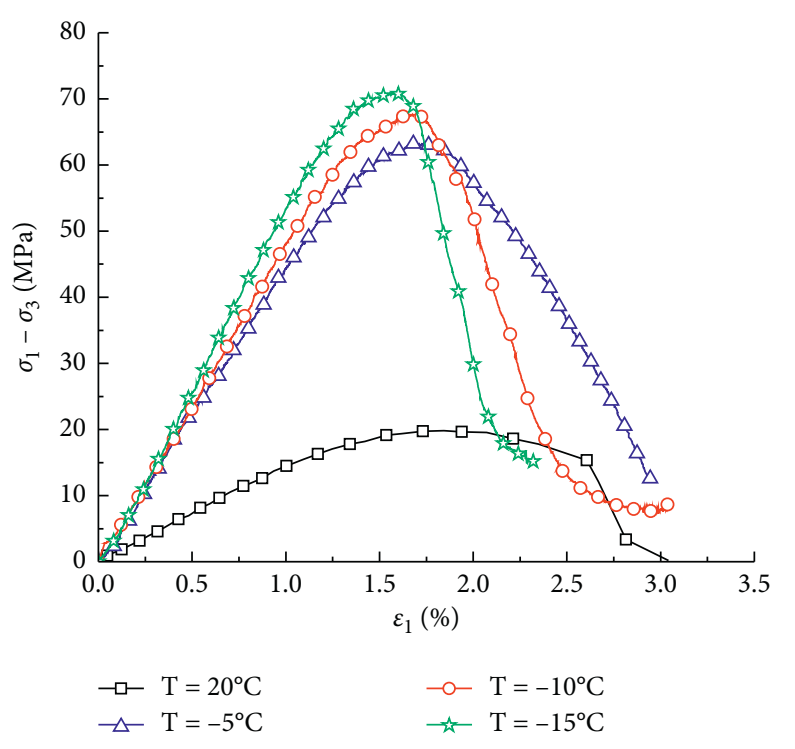

Figure 5: Stress-strain curve of sandstone at different temperatures $\left(\sigma_{3}=20 \mathrm{MPa}\right)$.

decreases after the peak stress. As the confining pressure increases, the peak stress of the $-10^{\circ} \mathrm{C}$ rock sample increases, and the peak strain increases.

3.2. Lateral Unloading Stress-Strain Curve of Sandstone at Different Temperatures. According to different temperature sandstone LUT data (initial confining pressure is $20 \mathrm{MPa}$ and the unloading rate is $0.2 \mathrm{MPa} / \mathrm{min}$ ), the relationships of deviatoric stress $\left(\sigma_{1}-\sigma_{3}\right)$, axial strain $\left(\varepsilon_{1}\right)$, and radial strain $\left(\varepsilon_{3}\right)$ are shown in Figure 7 . At the initial stage of unloading confining pressure of the $20^{\circ} \mathrm{C}$ rock sample, the stress-axial strain curve is approximately linear. After the peak stress, the deviatoric stress gradually decreases, and the rate of increase in axial and radial strain becomes higher. The freezing temperature decreases, the peak stress of lateral unloading increases, and the peak strain decreases. After the confining pressure unloading of the frozen sandstone begins, the axial and radial stress-strain curves first increase linearly, and the radial expansion and deformation are obvious under the action of lateral unloading. As the confining pressure continues to unload, the frozen sandstone enters the yield failure stage. Near the peak stress, there is a horizontal 


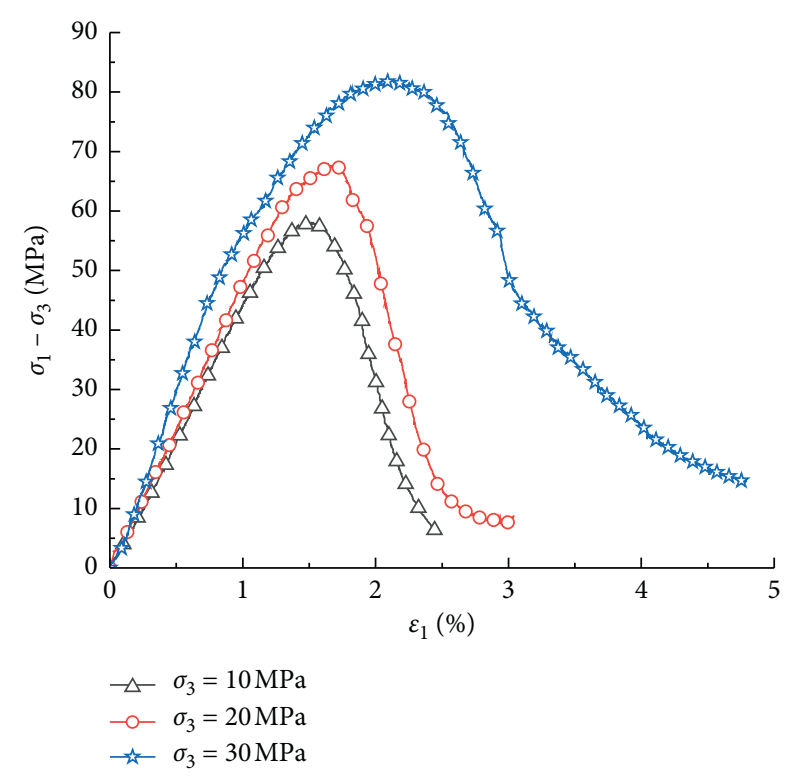

Figure 6: Stress-strain curves of sandstone with different confining pressures $\left(-10^{\circ} \mathrm{C}\right)$.

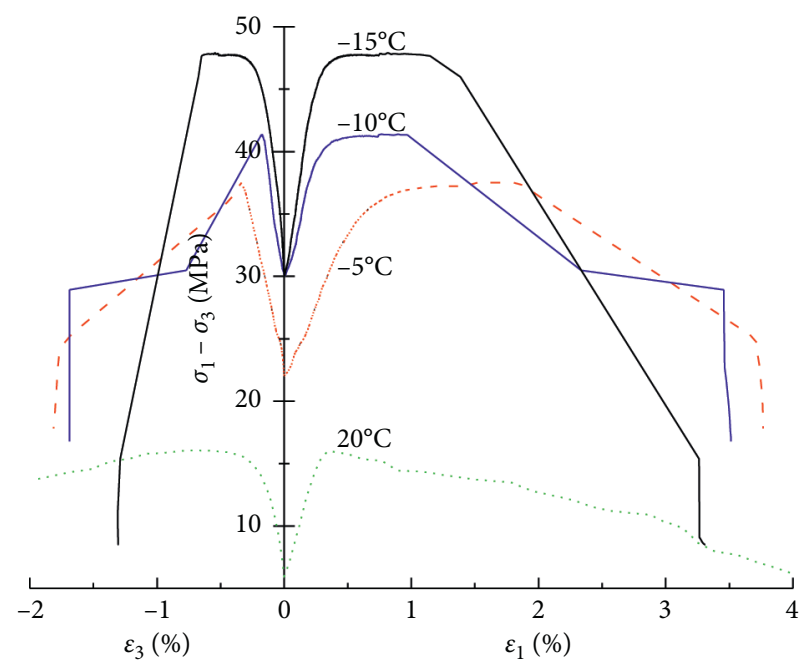

Figure 7: Stress-strain curves of lateral unloading sandstone at different temperatures $\left(\sigma_{3}^{0}=20 \mathrm{MPa}, V_{u}=0.2 \mathrm{MPa} / \mathrm{min}\right)$.

section of axial strain, which represents axial plastic flow. The displacement increase turning point is defined as the ultimate state of structural critical instability [31]. After the plastic flow stage, the deviator stress is greatly attenuated, and the axial compression strain and radial expansion strain increase unambiguously. The lateral unloading of frozen sandstone has more obvious brittle characteristics than triaxial compression. The lateral unloading failure of frozen sandstone is more severe and the instant of failure is accompanied by a larger crisp sound. Under lateral unloading, the peak stress of frozen sandstone is about $2 \sim 3$ times that of $20^{\circ} \mathrm{C}$ sandstone. The peak strain of $20^{\circ} \mathrm{C}$ sandstone is smaller than that of frozen sandstone. Frozen sandstone has more obvious brittle failure characteristics than $20^{\circ} \mathrm{C}$ sandstone.
3.3. Lateral Unloading Stress-Strain Curves of Frozen Sandstone under Different Initial Confining Pressures. The lateral unloading stress-strain curve of $-10^{\circ} \mathrm{C}$ sandstone under different initial confining pressures (unloading rate is $0.2 \mathrm{MPa} / \mathrm{min}$ ) is shown in Figure 8. As the initial confining pressure of frozen sandstone increases, the peak stress of lateral unloading increases, and the axial and radial strains increase. At the initial stage of unloading of confining pressure, the curves of stress and axial and radial strain increase approximately linearly. The greater the initial confining pressure, the greater the radial expansion and deformation caused by lateral unloading, and the more obvious the dominant effect of radial strain on the failure process of frozen sandstone. As the confining pressure continues to unload, the frozen sandstone enters the yield failure stage, and plastic flow occurs axially near the peak stress. The initial confining pressure increases and the plastic flow stage becomes shorter. Compared with the triaxial compression of frozen sandstone under the same confining pressure, the lateral unloading brittleness of frozen sandstone is more obvious. The lateral unloading failure of frozen sandstone is accompanied by a loud and crisp sound, the deviator stress attenuates greatly after the peak stress, and the axial and radial strain increase greatly.

3.4. Stress-Strain Curves of Frozen Sandstone under Different Lateral Unloading Rates. The stress-strain curve of $-10^{\circ} \mathrm{C}$ sandstone under different lateral unloading rates (initial confining pressure is $20 \mathrm{MPa}$ ) is shown in Figure 9. The lateral unloading rate increases, and the peak stress of lateral unloading of frozen sandstone increases. At the initial stage of unloading of confining pressure, the axial and radial stressstrain curves change linearly, the lateral unloading rate increases, and the axial and radial strains decrease. Continue to unload the confining pressure, the frozen sandstone enters the yield failure stage, the axial deformation curve has a horizontal section, the lateral unloading rate increases, and the horizontal section becomes shorter. Under the lateral unloading rate of $4 \mathrm{MPa} / \mathrm{min}$, the axial plastic flow of frozen sandstone is not obvious, while the brittleness characteristics are obvious. The instantaneous failure of the frozen sandstone is the loudest and most violent.

\section{Analysis and Discussion}

4.1. Influence of Temperature on Lateral Unloading Deformation of Sandstone. Lateral unloading causes internal cracks to propagate in the rock sample, leading to changes in deformation parameters. To study the change law of the deformation modulus during lateral unloading of frozen sandstone, the confining pressure unloading amount $\left(\Delta \sigma_{3}\right)$ and the amount of change in the deformation modulus $(\Delta E)$ are calculated according to the stress-strain curve; see equations (1) and (2), respectively.

$$
\Delta \sigma_{3}=\left(\frac{\sigma_{3}^{t}-\sigma_{3}^{0}}{\sigma_{3}^{0}-\sigma_{3}^{d}}\right) \times 100 \% \text {, }
$$




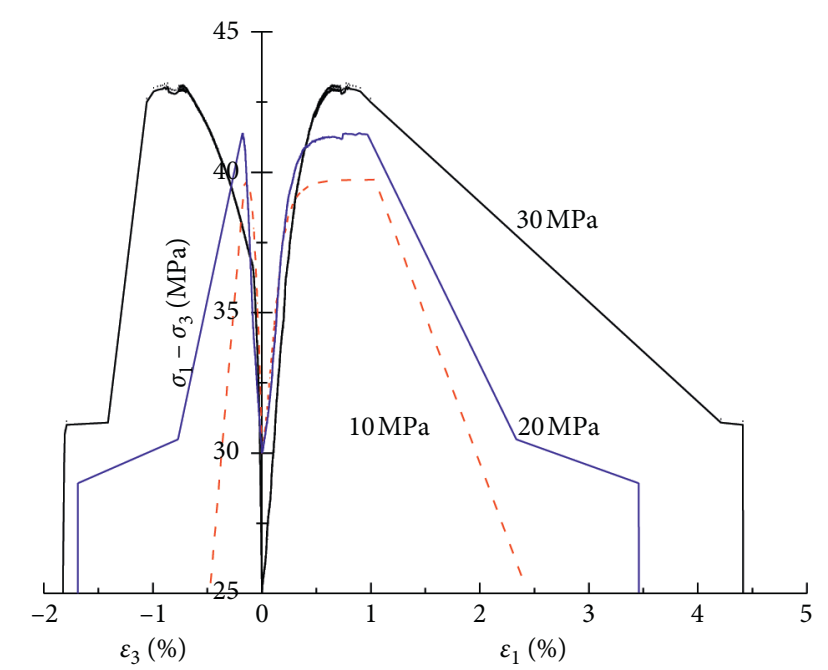

FIGURE 8: Lateral unloading stress-strain curves of frozen sandstone under different confining pressures $\left(-10^{\circ} \mathrm{C}, V_{u}=0.2 \mathrm{MPa} / \mathrm{min}\right)$.

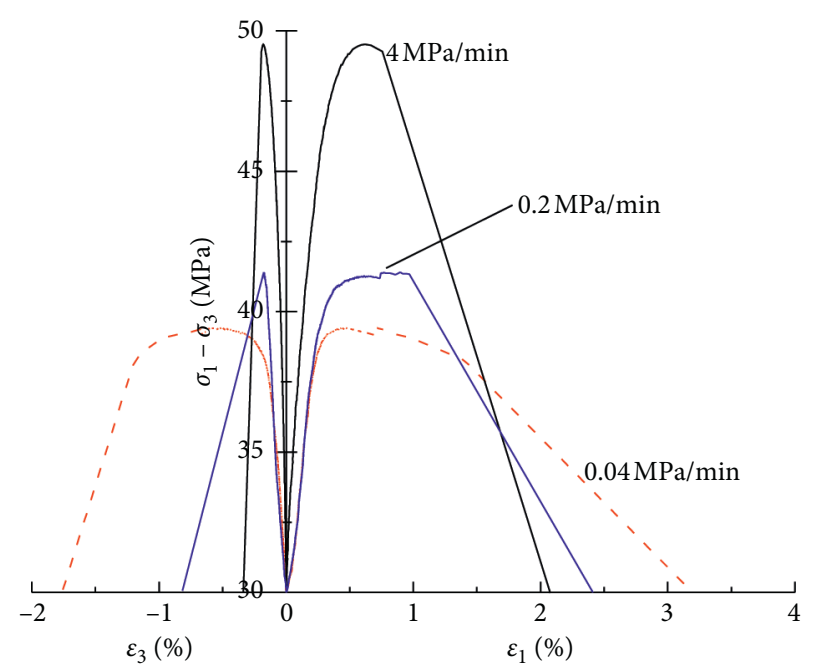

FIGURE 9: Stress-strain curves of frozen sandstone under different unloading rates $\left(-10{ }^{\circ} \mathrm{C}, \sigma_{3}^{0}=20 \mathrm{MPa}\right)$.

where $\sigma_{3}^{t}$ is the confining pressure corresponding to the unloading time $t, \sigma_{3}^{0}$ is the initial confining pressure of lateral unloading, and $\sigma_{3}^{d}$ is the confining pressure when the rock sample fails. All of the obtained $\Delta \sigma_{3}$ are negative values, indicating the direction of confining pressure unloading.

$$
\Delta E=\frac{E_{t}-E_{0}}{E_{0}} \times 100 \%
$$

where $E_{t}$ is the corresponding secant modulus at unloading time $t$ and $E_{0}$ is the initial deformation modulus before lateral unloading.

Under the initial confining pressure of $20 \mathrm{MPa}$, the sandstone at different temperatures is unloaded at a rate of $0.2 \mathrm{MPa} / \mathrm{min}$. In Figure 10 , the absolute value of the unloading amount of the confining pressure $\left(\Delta \sigma_{3}\right)$ is plotted on the horizontal axis, and the deviator stress $(\sigma)$, axial strain $\left(\varepsilon_{1}\right)$, and deformation modulus changes $(\Delta E)$ during the lateral unloading stage are plotted on the vertical axis. When the confining pressure unloading amount of the $20^{\circ} \mathrm{C}$ rock sample increases from $0 \%$ to $100 \%$, the deviator stress increases linearly. When the confining pressure unloading amount of $20^{\circ} \mathrm{C}$ rock samples increases from 0 to $90 \%$, the axial strain increases approximately linearly. However, when the confining pressure unloading amount increases from $90 \%$ to $100 \%$, the rate of increase in axial strain gradually becomes larger leading to failure.

As the confining pressure unloading amount of the frozen rock samples increases from 0 to $100 \%$, the deviator stress increases linearly. The freezing temperature of the rock sample decreases and the peak stress increases. When the confining pressure unloading amount increases from 0 to $70 \%$, the axial strain of the frozen rock sample increases approximately linearly. As the freezing temperature decreases, the rate of axial strain increase decreases. As the confining pressure unloading amount continues to increase, the rate of increase in axial strain gradually becomes larger. When the unloading amount of confining pressure increases from $90 \%$ to $100 \%$, the axial strain increases exponentially.

When the confining pressure unloading amount of the $20^{\circ} \mathrm{C}$ rock sample increases from 0 to $70 \%$, the deformation modulus increases at an increasing rate. As the unloading amount of confining pressure increases from $70 \%$ to $95 \%$, the rate of increase in the deformation modulus change was small. When the unloading amount of confining pressure increases from $95 \%$ to $100 \%$, the change in the deformation modulus reduces.

As the confining pressure unloading amount increases from 0 to $70 \%$, the rate of change in the deformation modulus of the rock sample at $-5^{\circ} \mathrm{C}$ gradually decreases; at $-15^{\circ} \mathrm{C}$, it gradually increases; at $-10^{\circ} \mathrm{C}$, it decreases first and then gradually stabilizes. This is because the rate of increase in stress was similar between the $-5^{\circ} \mathrm{C}$ and $-15^{\circ} \mathrm{C}$ rock samples. Due to low-temperature freezing, the strain increase rate of the $-5^{\circ} \mathrm{C}$ rock sample is unambiguously greater than that of the $-15^{\circ} \mathrm{C}$ rock sample. It is estimated that there must be a certain critical temperature between $-10^{\circ} \mathrm{C}$ and $-15^{\circ} \mathrm{C}$. At this temperature, the unloading amount of the confining pressure of the rock sample increases, and the amount of change in the deformation modulus remains stable. When the unloading amount of confining pressure is between $70 \%$ and $100 \%$, the frozen rock sample is in the stage of yield failure. As the unloading amount of confining pressure increases, the deformation modulus decreases at an increasing rate. As the freezing temperature of rock samples decreases, the unloading amount of confining pressure increases from $70 \%$ to $90 \%$, and the rate of decrease in the deformation modulus decreases. When the freezing temperature of rock samples decreases, the unloading amount of confining pressure increases from $90 \%$ to $100 \%$, and the rate of decrease in the deformation modulus increases.

Under the effect of freezing of saturated sandstone, the pore water phase becomes solid ice, and the rock skeleton is combined with the ice, which increases the average contact stress between particles. The lower the freezing temperature, the tighter the bond and the higher the overall bearing capacity of the frozen sandstone. During the confining 


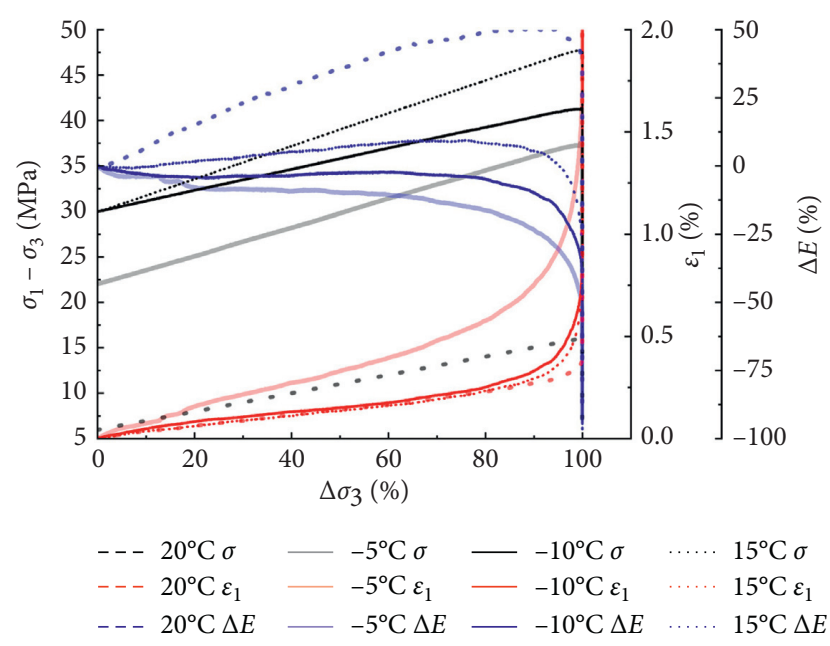

FIgURE 10: The relationship between sandstone $\Delta \sigma_{3}$ and deformation at different temperatures $\left(\sigma_{3}^{0}=20 \mathrm{MPa}, V_{u}=0.2 \mathrm{MPa} / \mathrm{min}\right)$.

pressure loading stage, the frozen sandstone skeleton and ice crystals both bear the confining pressure and the rock sample compresses and deforms in the axial and radial directions. During the axial compression loading stage, compression deformation continues to occur in the axial direction, and the radial direction gradually changes from compression deformation to expansion deformation. At the initial stage of confining pressure unloading, the confining pressure restraint of the solid skeleton and ice crystals of the rock sample in the horizontal direction gradually weakens, and the axial compression deformation and radial expansion deformation both increase; this occurs in the elastic unloading deformation stage. When the confining pressure is unloaded to a certain value, the frozen sandstone solid framework, ice crystals themselves and between each other produce horizontal tensile stress. As the confining pressure continues to unload, the tensile stress between the solid sandstone framework, the ice crystals, and the contact surface gradually increases. When the tensile strength is exceeded, cracks appear and propagate, radial deformation increases rapidly, and brittle failure occurs. Radial deformation dominates the lateral unloading failure process of frozen rock samples.

4.2. Influence of Initial Confining Pressure on Lateral Unloading Deformation of Frozen Sandstone. Under different confining pressures, the relationship between confining pressure unloading amount and deformation of $-10^{\circ} \mathrm{C}$ sandstone is shown in Figure 11. When the confining pressure unloading amount increases from 0 to $100 \%$, the deviator stress increases linearly. As the initial confining pressure increases, the deviator stress growth rate increases and the peak stress increases. When the confining pressure unloading amount increases from $0 \%$ to $70 \%$, the axial strain of the rock sample at $-10^{\circ} \mathrm{C}$ increases approximately linearly. As the initial confining pressure increases, the rate of axial strain increases. When the confining pressure unloading volume continues to increase, the rate of increase in axial strain gradually becomes larger. As the confining pressure unloading volume increases from $90 \%$ to $100 \%$, the axial strain increases exponentially.

As the confining pressure unloading amount of $-10^{\circ} \mathrm{C}$ rock samples increases from 0 to $70 \%$, the amount of change in the deformation modulus is relatively stable. The amount of change in the deformation modulus under an initial confining pressure of $10 \mathrm{MPa}$ is greater than that under $20 \mathrm{MPa}$ and $30 \mathrm{MPa}$. As the confining pressure unloading amount increases from $70 \%$ to $100 \%$, the rock sample is in the stage of yield failure, and the deformation modulus decreases at an increasing rate.

The triaxial compression strength of frozen rock samples increases with increasing confining pressure. The greater the initial confining pressure, the greater the initial axial pressure of the frozen rock sample in the LUT, the greater the compression deformation produced by the loading confining pressure, and the greater the axial and radial deformation produced by the unloading confining pressure. The main reasons are as follows:

(1) The initial confining pressure and initial axial pressure cause a certain amount of compression deformation of the frozen sandstone solid framework and ice crystals. The increase in the initial confining pressure and the initial axial pressure increases the compression deformation, and the rebound deformation caused by lateral unloading also increases.

(2) The initial confining pressure of frozen sandstone increases, and the initial axial pressure increases accordingly, and the releasable elastic energy stored inside increases. The lateral restraint effect of the rock sample gradually weakens at the stage of unloading confining pressure, and the elastic energy is converted into plastic deformation energy and released by radial deformation. The release of energy causes the lateral deformation rate of the rock sample to increase, the growth rate of axial strain increases, and the deformation modulus decreases at an increasing rate.

4.3. Analysis of Influence of Lateral Unloading Rate on Deformation of Frozen Sandstone. Under the initial confining pressure of $20 \mathrm{MPa}$, the confining pressure of $-10^{\circ} \mathrm{C}$ sandstone is unloaded at a rate of $0.04,0.2$, and $4 \mathrm{MPa} / \mathrm{min}$, respectively. The relationship between the confining pressure unloading amount and deformation is shown in Figure 12. As the confining pressure unloading amount increases from 0 to $100 \%$, the deviator stress increases linearly and the peak stress increases. As the confining pressure unloading amount increases from 0 to $70 \%$, the axial strain of the $-10^{\circ} \mathrm{C}$ rock sample increases linearly. The slope of the curve of $\Delta \sigma_{3}-\varepsilon_{1}$ at the unloading rate of $4 \mathrm{MPa} /$ min is less than that at the unloading rate of $0.04 \mathrm{MPa} / \mathrm{min}$ and $0.2 \mathrm{MPa} / \mathrm{min}$. As the confining pressure unloading amount increases from $70 \%$ to $100 \%$, the axial strain increases exponentially. 
As the unloading amount of confining pressure increases from 0 to $70 \%$, at a lateral unloading rate of $4 \mathrm{MPa} / \mathrm{min}$, the amount of change in the deformation modulus of the rock sample at $-10^{\circ} \mathrm{C}$ increases slightly and then stabilizes. At $0.04 \mathrm{MPa} / \mathrm{min}$ and $0.2 \mathrm{MPa} / \mathrm{min}$ lateral unloading rates, the amount of change in the deformation modulus of the rock sample at $-10^{\circ} \mathrm{C}$ decreases first and then gradually stabilizes, and the $\Delta \sigma_{3}-\Delta E$ curve is very close. At a high unloading rate $(4 \mathrm{MPa} / \mathrm{min})$, the energy stored in the frozen rock sample cannot be fully released through the deformation of the rock sample, less cracks develop, and the amount of change in the deformation modulus increases. At low unloading rates $(0.04 \mathrm{MPa} / \mathrm{min}$ and $0.2 \mathrm{MPa} / \mathrm{min})$, the unloading time is longer, and the energy accumulated in the frozen rock sample is fully released through the slow deformation of the rock sample. This produces rebound deformation, plastic deformation, partial creep deformation, and the deformation modulus changes substantially. When the unloading amount of confining pressure is between $70 \%$ and $100 \%$, the frozen sandstone is in the stage of yield failure. As the unloading amount of confining pressure increases, the rate of change in the deformation modulus decreases at an increasing rate.

As the confining pressure unloading rate of frozen rock samples increases, the axial and radial deformations decrease. The unloading rate mainly affects the failure of rock samples through radial deformation. The main reasons are as follows:

(1) Frozen rock samples cannot produce sufficient radial deformation in a short time under a high unloading rate. The elastic energy stored in the frozen rock sample cannot be released in time through lateral expansion, resulting in low unloading deformation.

(2) At a low unloading rate, the unloading duration of confining pressure is longer, and the frozen rock sample has produced sufficient springback deformation, while also producing a certain amount of creep deformation. The amount of plastic deformation before the instability failure is large, resulting in a large amount of unloading deformation. The higher the confining pressure unloading rate, the shorter the excavation period of the frozen shaft and the lower the surrounding rock deformation. Before the completion of the supporting structure, whether the maximum lateral deformation of the surrounding rock meets relevant safety requirements should be considered. Then, a reasonable excavation and unloading confining pressure rate should be formulated.

4.4. Lateral Unloading Strength of Frozen Sandstone. A comparison of the peak stress of frozen sandstone lateral unloading and the peak stress of triaxial compression is shown in Figure 13.

(1) Under the initial confining pressure of $20 \mathrm{MPa}$, the peak stresses of $20^{\circ} \mathrm{C},-5^{\circ} \mathrm{C},-10^{\circ} \mathrm{C}$, and $-15^{\circ} \mathrm{C}$ sandstone under triaxial compression are $19.14 \mathrm{MPa}$,
63.41 $\mathrm{MPa}, 67.73 \mathrm{MPa}$, and $70.86 \mathrm{MPa}$, respectively, and the lateral unloading peak stresses are, respectively, 16.09 $\mathrm{MPa}$, 37.57 $\mathrm{MPa}$, 41.4 MPa, and 47.88 $\mathrm{MPa}$. The peak stress of lateral unloading of rock samples accounted for $84.1 \%, 59.2 \%, 61.1 \%$, and $67.6 \%$ of the peak stress of triaxial compression, respectively. As the freezing temperature decreases, the ratio gradually increases. As the temperature of the rock sample decreases, the rate of increase in the peak stress in triaxial compression is slightly lower than that of the peak stress in lateral unloading.

(2) Under the initial confining pressure of $10 \mathrm{MPa}$, $20 \mathrm{MPa}$, and $30 \mathrm{MPa}$, the peak stress of triaxial compression of $-10^{\circ} \mathrm{C}$ sandstone is $58.02 \mathrm{MPa}, 67.73 \mathrm{MPa}$, and $82.03 \mathrm{MPa}$, and the peak stress of lateral unloading is $39.38 \mathrm{MPa}, 41.4 \mathrm{MPa}$, and $43.08 \mathrm{MPa}$, respectively. The peak stress of lateral unloading of rock samples accounted for $67.9 \%, 61.1 \%$, and $52.5 \%$ of the peak stress of triaxial compression, respectively. As the initial confining pressure increases, the proportion decreases significantly. The initial confining pressure of $-10^{\circ} \mathrm{C}$ sandstone increases, and the rate of increase in the peak stress of triaxial compression is greater than that of the peak stress of lateral unloading. The greater the initial confining pressure, the more obvious the strength attenuation effect under lateral unloading conditions.

(3) At $0.04 \mathrm{MPa} / \mathrm{min}, 0.2 \mathrm{MPa} / \mathrm{min}$, and $4 \mathrm{MPa} / \mathrm{min}$ lateral unloading rates, the peak stresses of $-10^{\circ} \mathrm{C}$ sandstone lateral unloading are $39.42 \mathrm{MPa}, 41.4 \mathrm{MPa}$, and $49.26 \mathrm{MPa}$, respectively. As the unloading rate increases, the lateral unloading peak stress of the rock sample increases, accounting for $58.2 \%, 61.1 \%$, and $72.7 \%$ of the peak stress in triaxial compression under the same conditions, and the proportion gradually increases. Lateral unloading of frozen sandstone causes more damage than triaxial compression.

Cretaceous sandstone contains swelling clay minerals and hydration softens the rock skeleton. Unfrozen water cannot resist shear forces. When the hole walls are forced into contact, the combined water film reduces the friction between the hole walls and the strength of the rock sample is reduced [32]. The mechanical changes in frozen rock mainly depend on the phase change of the water-ice system. When the temperature of the rock sample drops from $0^{\circ} \mathrm{C}$ to $-5^{\circ} \mathrm{C}$, the bound water and capillary water are significantly reduced. When the temperature of the rock sample drops from $-5^{\circ} \mathrm{C}$ to $-15^{\circ} \mathrm{C}$, the capillary water gradually decreases, and the bound water shows a fluctuating downward trend [33]. Ice in pores can act both as a cementing material providing adhesion force under tension and a filling material providing sustaining force under compression. During the lateral unloading failure process of sandstone with different freezing temperatures, the axial strain increases linearly with time, and microcracks appear and extend in the weaker medium. Since the strength of sandstone particles is greater than the strength of ice crystals, the main reasons are that the ice crystals are broken and the ice crystals and sandstone 


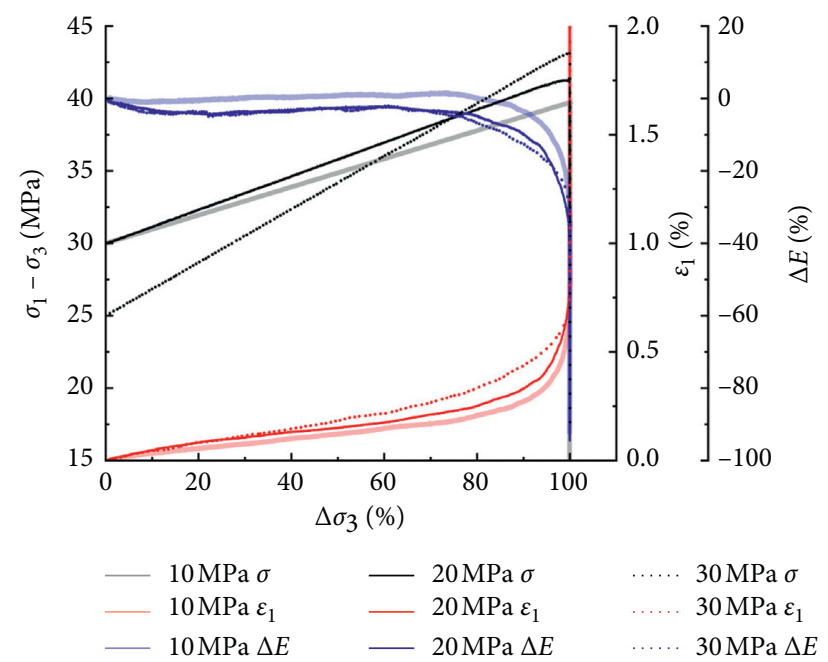

Figure 11: The relationship curve between $\Delta \sigma_{3}$ and deformation of $-10^{\circ} \mathrm{C}$ sandstone under different initial confining pressures $\left(V_{u}=0.2 \mathrm{MPa} / \mathrm{min}\right)$.

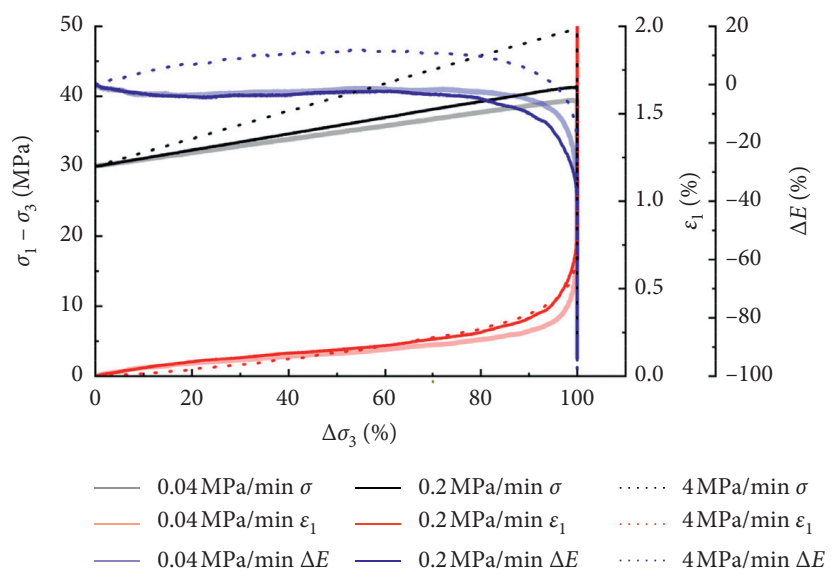

Figure 12: The relationship curve between $\Delta \sigma_{3}$ and deformation of $-10^{\circ} \mathrm{C}$ sandstone under different unloading rates $\left(\sigma_{3}^{0}=20 \mathrm{MPa}\right)$.

cements are debonded to produce microcracks. As the freezing temperature decreases, the bearing capacity of the ice crystals increases, the bond with the solid sandstone becomes stronger, and the overall strength of the frozen sandstone increases. As the freezing temperature decreases, the peak stress of sandstone increases, the axial deformation decreases, the dissipated strain energy used for plastic deformation decreases, the elastic deformation energy stored inside increases, and the damage is more substantial at the moment of failure.

\subsection{Deformation and Failure of Frozen Sandstone in Lateral} Unloading. Using electronic image processing equipment, the side cylinder of the damaged rock sample is expanded into a plan view, as shown in Figure 14.
(1) The $20^{\circ} \mathrm{C}$ rock sample was split axially by a slightly inclined crack, showing a certain degree of shear friction. The crack zone is wide, the sandstone at the crack is broken and loose, and there is a transverse crack in the middle of the rock sample, which is the most severely broken. The $-5^{\circ} \mathrm{C}$ rock sample was split axially by a crack. The crack splits from the upper part of the rock sample and extends to the lower part. Without being penetrated by cracks, the rock sample has lost its bearing capacity. The $-10^{\circ} \mathrm{C}$ rock sample was split vertically by a crack, and the section was neat. The splitshear cracks in the upper part of the $-15^{\circ} \mathrm{C}$ rock sample develop together, and the upper indenter and the rock sample froze more firmly. The axial load is applied by the upper indenter, and the upper indenter and the rock sample slip and cause friction, resulting in additional 


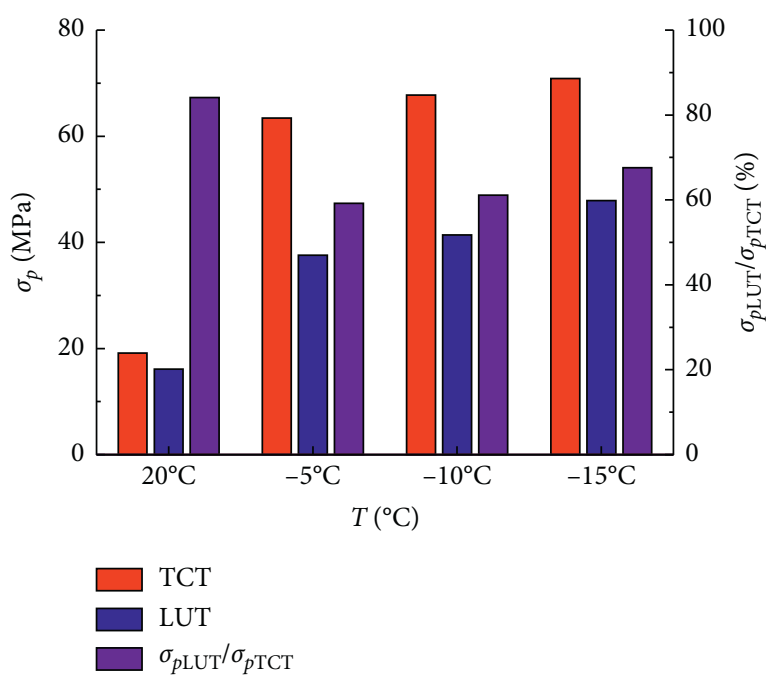

(a)

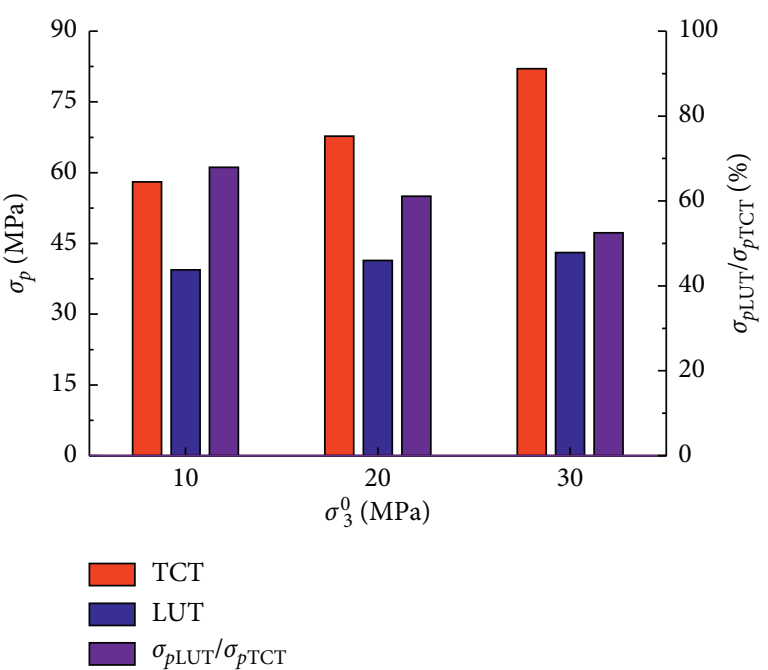

(b)

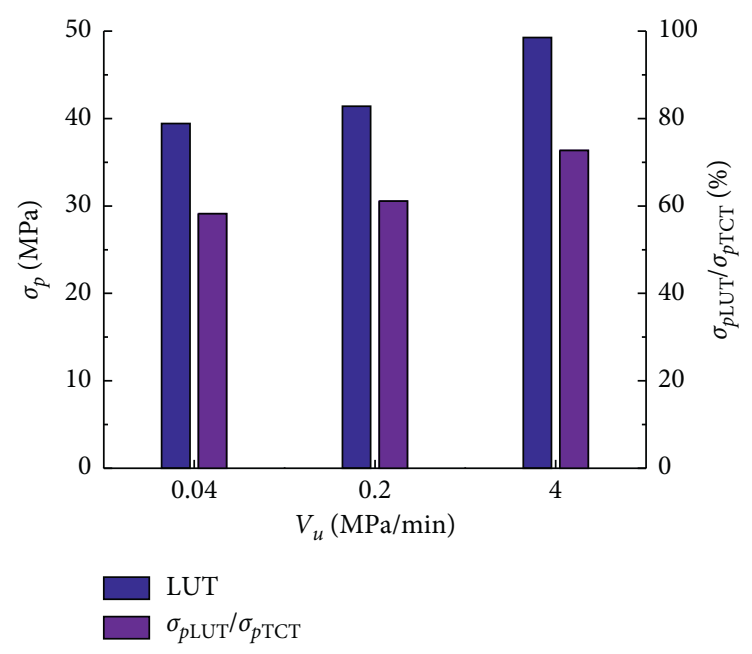

(c)

FIGURE 13: Comparison of peak stress of lateral unloading and peak stress of triaxial compression ( $\sigma_{p}$ : peak stress, $\sigma_{p \mathrm{LUT}} / \sigma_{p \mathrm{TCT}}$ : ratio of the peak stress of lateral unloading to the peak stress of triaxial compression). (a) Different temperature. (b) Different confining pressure. (c) Different lateral unloading rates.

local shear stress, and the coexistence of splitting and shearing at the upper end of the rock sample. The upper end of the rock sample was severely fragmented. The cementation of ice and particles improves the integrity of the rock and increases brittleness.

(2) Under the initial confining pressure of $10 \mathrm{MPa}$, two axial cracks split the frozen rock sample into three pieces. Under the initial confining pressure of $30 \mathrm{MPa}$, the axial cracks of the frozen rock sample are three-stage polyline, showing the main splitting action and the secondary shearing action. Low initial confining pressure is conducive to the generation of tensile cracks. Under high initial confining pressure, tensile cracks develop slowly and tortuously, showing a certain shearing effect. Under a low initial confining pressure, tensioning cracks could be generated, while under a high initial confining pressure, tensioning cracks developed slowly in a zigzag pattern, showing a certain shear action.

(3) At $0.04 \mathrm{MPa} / \mathrm{min}$ and $0.2 \mathrm{MPa} / \mathrm{min}$ lateral unloading rates, a single axial crack splits the frozen rock sample vertically, and the section is neat. At a lateral unloading rate of $4 \mathrm{MPa} / \mathrm{min}$, a main crack in the axial direction splits the frozen rock sample vertically, and a transverse crack divides the rock sample on the right side into two pieces. Under a high unloading rate, the rock sample swells rapidly in the lateral direction, and the surface expansion deformation is greater than the middle expansion deformation, resulting in hoop tensile cracks, forming crisscross cracks. 


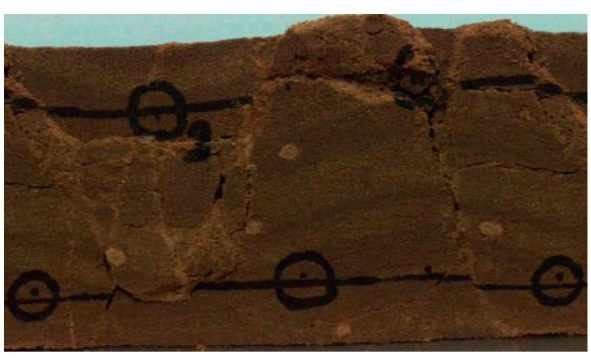

(a)

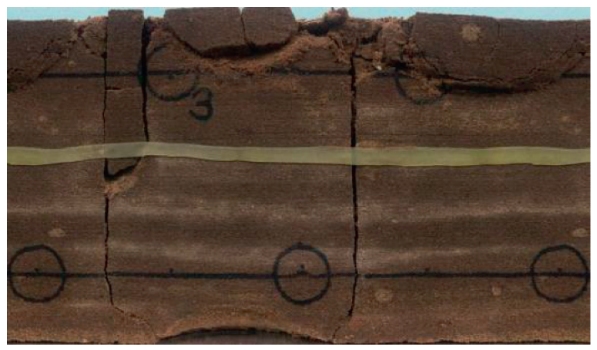

(c)

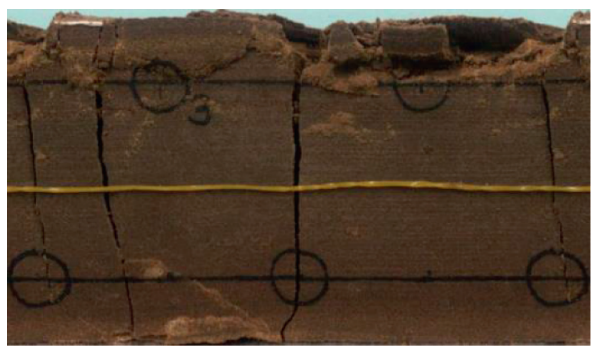

(e)

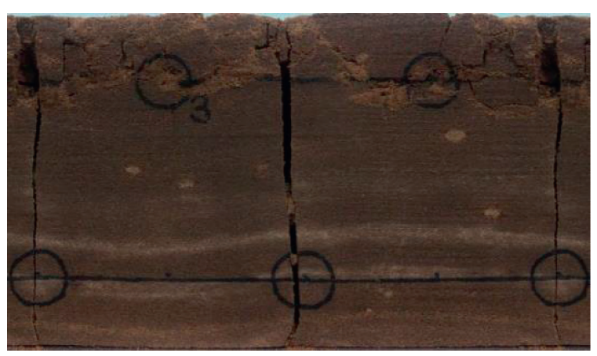

(g)

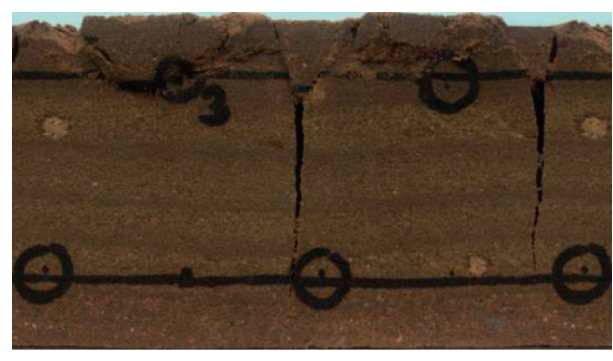

(b)

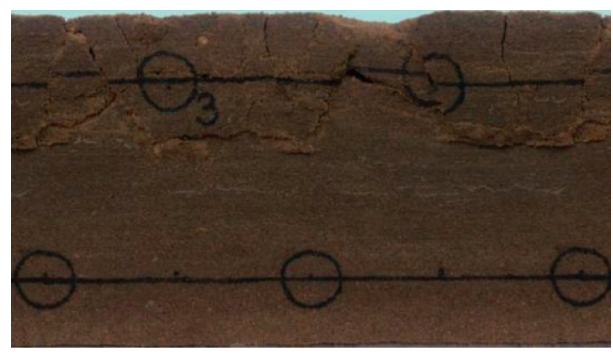

(d)

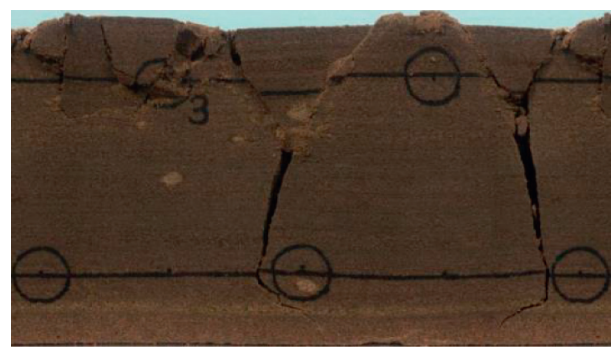

(f)

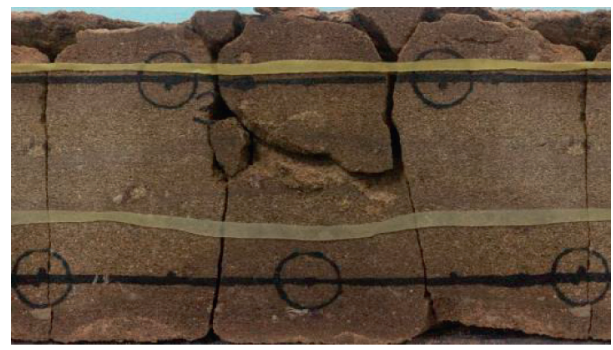

(h)

Figure 14: Side elevation view of frozen rock sample lateral unloading failure. (a) $20^{\circ} \mathrm{C}, \sigma_{3}=20 \mathrm{MPa}, V_{u}=0.2 \mathrm{MPa} / \mathrm{min}$. (b) $-5^{\circ} \mathrm{C}$, $\sigma_{3}=20 \mathrm{MPa}, V_{u}=0.2 \mathrm{MPa} / \mathrm{min}$. (c) $-10^{\circ} \mathrm{C}, \sigma_{3}=20 \mathrm{MPa}, V_{u}=0.2 \mathrm{MPa} / \mathrm{min}$. (d) $-15^{\circ} \mathrm{C}, \sigma_{3}=20 \mathrm{MPa}, V_{u}=0.2 \mathrm{MPa} / \mathrm{min}$. (e) $-10^{\circ} \mathrm{C}$, $\sigma_{3}=10 \mathrm{MPa}, V_{u}=0.2 \mathrm{MPa} / \mathrm{min}$. (f) $-10^{\circ} \mathrm{C}, \sigma_{3}=30 \mathrm{MPa}, V_{u}=0.2 \mathrm{MPa} / \mathrm{min}$. (g) $-10^{\circ} \mathrm{C}, \sigma_{3}=20 \mathrm{MPa}, V_{u}=0.04 \mathrm{MPa} / \mathrm{min}$. (h) $-10^{\circ} \mathrm{C}$, $\sigma_{3}=20 \mathrm{MPa}, V_{u}=4 \mathrm{MPa} / \mathrm{min}$.

\section{Conclusions}

To study the deformation and failure of the artificial freezing method through the deep and thick Cretaceous water-rich soft rock layer, lateral unloading mechanics tests were carried out with different freezing temperatures, different initial confining pressures, and different unloading rates.

The conclusions are as follows:
(1) Under the initial confining pressure of $20 \mathrm{MPa}$, the lateral unloading peak stress of frozen sandstone is about 2 3 times that of $20^{\circ} \mathrm{C}$ sandstone. As the freezing temperature decreases, the axial and radial strains decrease, and the rate at which peak stress increases in triaxial compression is slightly lower than the rate of peak stress increase in lateral unloading. As the confining pressure unloading 
amount of the $20^{\circ} \mathrm{C}$ rock sample increases from 0 to $95 \%$, and then to $100 \%$, the amount of change in the deformation modulus first increases and then decreases. As the confining pressure unloading amount increases from 0 to $70 \%$, the amount of change in the deformation modulus of the rock sample at $-5^{\circ} \mathrm{C}$ gradually decreases; at $-10^{\circ} \mathrm{C}$ it first decreases and then gradually stabilizes; and at $-15^{\circ} \mathrm{C}$ it gradually increases. As the unloading amount of confining pressure increases from $70 \%$ to $100 \%$, the freezing temperature of the rock sample decreases, and the deformation modulus decreases at an increasing rate.

(2) As the initial confining pressure of frozen sandstone increases, the axial and radial strain growth rates of lateral unloading increase. The radial strain dominates the failure process. The rate of peak stress increase in triaxial compression is greater than that of the lateral unloading peak stress. Lateral unloading strength attenuation occurs unambiguously. As the confining pressure unloading amount increases from 0 to $70 \%$, the initial confining pressure of $10 \mathrm{MPa}$ is greater than the amount of change in the deformation modulus under the initial confining pressure of $20 \mathrm{MPa}$ and $30 \mathrm{MPa}$. As the confining pressure unloading amount increases from $70 \%$ to $100 \%$, the initial confining pressure increases, and the deformation modulus decreases at an increasing rate.

(3) As the unloading rate of frozen sandstone increases, the peak stress of lateral unloading increases, the axial and radial strain decrease, and the ratio of the peak stress of lateral unloading to the peak stress of triaxial compression increases. As the confining pressure unloading amount increases from 0 to $70 \%$, under an unloading rate of $4 \mathrm{MPa} / \mathrm{min}$, the amount of change in the deformation modulus increases slightly and then stabilizes. Under unloading rates of $0.04 \mathrm{MPa} / \mathrm{min}$ and $0.2 \mathrm{MPa} / \mathrm{min}$, the amount of change in the deformation modulus decreases first and then gradually stabilizes. As the confining pressure unloading amount increases from $70 \%$ to $100 \%$, the the deformation modulus changes even less. The frozen rock sample undergoes tensile splitting failure during lateral unloading. By changing the construction speed of the freezing method, the surrounding rock deformation can be appropriately reduced.

\section{Data Availability}

No data were used to support this study.

\section{Conflicts of Interest}

The authors declare that they have no conflicts of interest.

\section{Acknowledgments}

This work was supported by the National Natural Science Foundation of China (Grants nos. 51774231 and 41702339).

\section{References}

[1] E. Pimentel, S. Papakonstantinou, and G. Anagnostou, "Numerical interpretation of temperature distributions from three ground freezing applications in urban tunnelling," Tunnelling and Underground Space Technology, vol. 28, no. 3, pp. 57-69, 2012.

[2] Q. Zeng, "Discussion of "freezing strain model for estimating the unfrozen water content of saturated rock under low temperature" by shibing huang, Quansheng Liu, Yanzhang Liu, Zuyang Ye, and aiping Cheng (Note)," International Journal of Geomechanics, vol. 19, no. 7, pp. 1-5, 2019.

[3] Y. J. Shen, Y. Yang, G. S. Yang et al., “'Damage characteristics and thermo-physical properties changes of limestone and sandstone during thermal treatment from $-30^{\circ} \mathrm{C}$ to $1000^{\circ} \mathrm{C}$," Heat and Mass Transfer, vol. 54, no. 4, pp. 3389-3407, 2018.

[4] L. Liu, X. Liu, Z. Li, Z. Yao, and G. Cai, "Experimental analysis on the mechanical properties of saturated silty mudstone under frozen conditions," Journal of Testing and Evaluation, vol. 47, no. 1, pp. 188-202, 2019.

[5] J. Kodama, T. Goto, Y. Fujii, and P. Hagan, "The effects of water content, temperature and loading rate on strength and failure process of frozen rocks," International Journal of Rock Mechanics and Mining Sciences, vol. 62, pp. 1-13, 2013.

[6] F. Gao, C. Cai, and Y. Yang, "Experimental research on rock fracture failure characteristics under liquid nitrogen cooling conditions," Results in Physics, vol. 9, no. 5, pp. 252-262, 2018.

[7] R. L. Shan, Y. W. Song, L. W. Song, and Y. Bai, "Dynamic property tests of frozen red sandstone using a split hopkinson pressure bar," Earthquake Engineering and Engineering Vibration, vol. 18, no. 3, pp. 511-519, 2019.

[8] M. Jia, Z. Z. Yang, Y. P. Zhang, X. G. Li, and N. Y. Zhou, "Plugging ability of ice crystals in a low temperature coal rock fracture," Chemistry and Technology of Fuels and Oils, vol. 55, no. 4, pp. 483-490, 2019.

[9] J. W. Yue, G. W. Yue, Z. F. Wang, M. M. Li, B. B. Wang, and F. H. An, "Freezing method for rock cross-cut coal uncovering I: mechanical properties of a frozen coal seam for preventing outburst," Scientific Reports, vol. 9, no. 1, pp. 1-17, 2019.

[10] Z. Q. Li, F. Hu, S. W. Qi, and R. L. Hu, "Strain-softening failure mode after the post-peak as a unique mechanism of ruptures in a frozen soil-rock mixture," Engineering Geology, vol. 274, pp. 1-11, 2020.

[11] C. Xia, Z. Lv, Q. Li, J. Huang, and X. Bai, “Transversely isotropic frost heave of saturated rock under unidirectional freezing condition and induced frost heaving force in cold region tunnels," Cold Regions Science and Technology, vol. 152, pp. 48-58, 2018.

[12] J. Yu, X. Chen, H. Li, J.-w. Zhou, and Y.-y. Cai, "Effect of freeze-thaw cycles on mechanical properties and permeability of red sandstone under triaxial compression," Journal of Mountain Science, vol. 12, no. 1, pp. 218-231, 2015.

[13] M. Vikram and B. M. Julian, "Micro-computed tomography imaging and probabilistic modelling of rock fracture by freeze-thaw," Earth Surface Processes and Landforms, vol. 45, no. 3, pp. 666-680, 2020.

[14] X. Fang, J. Xu, and P. Wang, "Compressive failure characteristics of yellow sandstone subjected to the coupling effects of chemical corrosion and repeated freezing and thawing," Engineering Geology, vol. 233, pp. 160-171, 2018.

[15] T. L. Han, J. P. Shi, and X. S. Cao, "Fracturing and damage to sandstone under coupling effects of chemical corrosion and freeze-thaw cycles," Rock Mechanics and Rock Engineering, vol. 49, no. 11, pp. 4245-4255, 2016. 
[16] S. L. Qiu, X. T. Feng, J. Q. Xiao, and C. Q. Zhang, "An experimental study on the pre-peak unloading damage evolution of marble," Rock Mechanics and Rock Engineering, vol. 47, no. 8, pp. 401-419, 2014.

[17] S.-q. Yang, H.-m. Ni, and S. Wen, "Spatial acoustic emission evolution of red sandstone during multi-stage triaxial deformation," Journal of Central South University, vol. 21, no. 8, pp. 3316-3326, 2014.

[18] S. Q. Yang, H. W. Jing, and S. Y. Wang, "Experimental investigation on the strength, Deformability, Failure behavior and acoustic emission locations of red sandstone under triaxial compression," Rock Mechanics and Rock Engineering, vol. 45, no. 7, pp. 583-606, 2012.

[19] X. T. Xu, R. Q. Huang, H. Li, and Q. X. Huang, "Determination of Poisson's ratio of rock material by changing axial stress and unloading lateral stress test," Rock Mechanics and Rock Engineering, vol. 48, no. 6, pp. 853-857, 2015.

[20] D.-m. Zhang, Y.-s. Yang, Y.-p. Chu, X. Zhang, and Y.-g. Xue, "Influence of loading and unloading velocity of confining pressure on strength and permeability characteristics of crystalline sandstone," Results in Physics, vol. 9, no. 3, pp. 1363-1370, 2018.

[21] X. G. Zhao, J. Wang, M. Cai et al., "Influence of unloading rate on the strainburst characteristics of Beishan granite under true-triaxial unloading conditions," Rock Mechanics and Rock Engineering, vol. 47, no. 2, pp. 467-483, 2014.

[22] X. Huang, Q. S. Liu, B. Liu, X. W. Liu, Y. C. Pan, and J. P. Liu, "Experimental study on the dilatancy and fracturing behavior of soft rock under unloading conditions," International Journal of Civil Engineering, vol. 15, no. 7, pp. 921-948, 2017.

[23] F. Feng, S. Chen, D. Li, W. Huang, K. Peng, and C. Zang, "Excavation unloading-induced fracturing of hard rock containing different shapes of central holes affected by unloading rates and in situ stresses," Energy Science \& Engineering, vol. 8, no. 1, pp. 4-27, 2020.

[24] D. Huang and Y. Li, "Conversion of strain energy in triaxial unloading tests on marble," International Journal of Rock Mechanics and Mining Sciences, vol. 66, no. 3, pp. 160-168, 2014.

[25] K. Duan, Y. Ji, W. Wu, and C. Y. Kwok, "Unloading-induced failure of brittle rock and implications for excavation-induced strain burst," Tunnelling and Underground Space Technology, vol. 84, pp. 495-506, 2019.

[26] M. C. He, J. L. Miao, and J. L. Feng, "Rock burst process of limestone and its acoustic emission characteristics under truetriaxial unloading conditions," International Journal of Rock Mechanics and Mining Sciences, vol. 47, no. 2, pp. 286-298, 2010.

[27] H. Xu, X.-T. Feng, C. Yang, X. Zhang, Y. Zhou, and Z. Wang, "Influence of initial stresses and unloading rates on the deformation and failure mechanism of Jinping marble under true triaxial compression," International Journal of Rock Mechanics and Mining Sciences, vol. 117, pp. 90-104, 2019.

[28] T. Xiao, M. Huang, and M. Gao, "Experimental study of the mechanical characteristics of a rock-like material containing a preexisting fissure under loading and unloading triaxial compression," Advances in Civil Engineering, vol. 2020, Article ID 9374352, 12 pages, 2020.

[29] X. Li, W. Cao, Z. Zhou, and Y. Zou, "Influence of stress path on excavation unloading response," Tunnelling and Underground Space Technology, vol. 42, pp. 237-246, 2014.

[30] Y. G. Yang, M. K. Liao, H. B. Cai, and P. J. Chen, "Numerical simulation of the temperature fields in the shielding walls of frozen soil with multi-circle-pipe freezing in shaft sinking," Thermal Science, vol. 23, no. 3, pp. 647-652, 2019.

[31] Q. Jiang, X. Liu, F. Yan, Y. Yang, D. Xu, and G. Feng, "Failure performance of 3DP physical twin-tunnel model and corresponding safety factor evaluation," Rock Mechanics and Rock Engineering, vol. 54, no. 1, pp. 109-128, 2021.

[32] H. L. Jia, F. Zi, G. S. Yang et al., "Influence of pore water (ice) content on the strength and deformability of frozen argillaceous siltstone," Rock Mechanics and Rock Engineering, vol. 53, no. 2, pp. 967-974, 2020.

[33] H. L. Jia, S. Ding, Y. Wang, F. Zi, Q. Sun, and G. S. Yang, “An NMR-based investigation of pore water freezing process in sandstone," Cold Regions Science and Technology, vol. 168, 2018. 